\title{
ANALYSIS OF MAXILLARY BONE THICKNESS AT INCISOR AREA IN CLASS II DIVISION 1 MALOCCLUSION
}

\author{
Dr. Manju Bajracharya \\ Lecturer, People's Dental College, Kathmandu \\ Email: manjub79@hotmail.com
}

\section{ABSTRACT}

Objectives: To determine and analyze the maxillary incisal jaw bone thickness among different vertical skeletal facial types of Class II Division 1 malocclusion. Materials and method: The samples $(n=121)$ between $12-14$ yrs of age were divided into three groups (low angle, average angle, high angle) based on their SN-MP angle. Linear measurements were processed and analyzed statistically. The characteristics of abnormal incisor jaw bone thickness at upper and lower incisors among three vertical facial skeletal types were studied in detail. Results: At the upper and lower central incisors low angle individuals presented greater dentoalveolar, basal bone thickness than high and average angle individuals. The distance from the root apex of upper and lower central incisors were far away from the lingual cortex in low angle than high angle individuals. Conclusion: Among different vertical facial types with Class II Division 1 malocclusion in early permanent dentition may accord to establish discriminate values as a sample to set up the cephalometric standard for the appropriate diagnosis to provide better treatment plan for the clinicians.

Key words: Cephalometrics, Class II Division 1 malocclusion, Incisor jaw bone, Maxillary bone

\section{INTRODUCTION}

Orthodontists have been interested in the multitude of differences in diagnosis and treatment response between different vertical skeletal patterns. It is generally believed that the cortical plates of the incisal alveolar bone are the "anatomic limitations" for tooth movement. ${ }^{3-5}$ To some malocclusion sufferers, like non growing individuals these "anatomic limitations" were often considered an important factor in selecting the therapeutic effect. ${ }^{7}$ The attempt of extensive palatal movement of maxillary incisors were done by several investigators. ${ }^{2-5}$ Roots of these teeth brought into contact with palatal cortex led to bend and remodel to some extent; further orthodontic tooth movement led to cortical plate penetration and subsequent bone loss and root resorption. ${ }^{9,12-16}$

The principle objective of treating Class II Division 1 malocclusion is the reduction in the overjet and is usually performed in the mixed dentition. As the age advances, slow down of facial growth and permanent dentition replacing deciduous teeth require some teeth extraction prior to treatment mechanics. Therefore, the purpose of this study was to investigate how much retraction of maxillary incisors were possible for overjet correction and anterior maxillary and mandibular cortical bone remodeling by determining and analyzing incisal jaw morphology of maxillary bone in Class II Division 1 malocclusion among the Chinese population.

\section{AIMS AND OBJECTIVE}

1. To determine and analyze the maxillary bone thickness at incisor area in Class II Division 1 malocclusion having three vertical skeletal facial types such as High angle, Average angle and Low angle Chinese subjects of early permanent dentition.

2. To investigate possible differences between Chinese male and female patients.

\section{MATERIALS AND METHOD}

The retrospective study was performed using lateral cephalograms available from Department of Orthodontics of the affiliated hospital of Chongqing Medical University, Chongqing, China of 121 subjects (54 males, 67 females) aged between 12-14 years. The selection was based on $\mathrm{SN}$ MP angle divided into 3 vertical skeletal facial types having High angle group (male 11, female 19), Average angle group (male 27, female 32) and Low angle group (male 16, female 16). The SN-MP angle for high angle group was $>40^{\circ}$ 
degrees, for average angle group was between $29-40^{\circ}$ and for low angle groups was $<29^{\circ}$ for both male and female individuals.

The samples were included having good quality cephalometric record, no previous history of orthodontic treatment, Angle's Class II Division 1 malocclusion with overjet $>=4 \mathrm{~mm}$ with or without open bite, no obvious craniofacial deformity, systemic disease, all permanent teeth present including second molars and presence of no restorations on incisal edges of upper and lower central incisors.

The lateral cephalometric radiographs were saved in JPEG format and measured in winceph software version 8 . Following 30 points having 16 anatomical landmarks for linear measurements as defined by Handelmann et al, ${ }^{11}$ Akira et $a l^{19}$ and Beckmann et $a^{20}$ were used (Figure $1 \& 2$ ).

\section{S, 2. N, 3. ANS, 4. PNS, 5. A point, 6. ULP (upper labial} alveolar bone margin), 7. UPP(upper palatal alveolar bone margin), 8. UM (maxillary alveolar meatus mid point), 9. UI (upper incisor edge tip), 10. UIR (upper incisor roor apex), 11. PA (palatal counterpart of point A), 12. PC, 13. UCL (upper labial alveolar cortex), 14. UBaM, 15. P, 16. Go, 17. Gn, 18. Me, 19. D point, 20. B point, 21. LLP (lower labial alveolar bone margin), 22. LTP (lower palatal alveolar bone edge), 23. LM (mandibular alveolar meatus mid point), 24. LI (lower incisor edge tip), 25. LIR (lower incisor root apex), 26. TB (intersection between a perpendicular to the mandibular axis through point $\mathrm{B}$ and lower lingual border of symphysis), 27. LBaM (mid point between B, TB), 28. TC (point on the posterior symphysial border, most distant from the mandibular alveolar axis), 29. LLC (lower labial cortex), 30. Sb (intersection between lower border of symphysis and mandibular alveolar axis).

Systematic errors detected by using paired student's t- test of randomly selected 10 cephalograms indicated no statistically significant difference between first and second measurements. All statistical analysis was performed with SPSS Windows version 10.0. Mean and standard deviations were calculated for each measurement. Analysis of variance (ANOVA) test was performed to access the difference occurring among the three groups. Also, independent t-test was used to determine the difference between male and female in each group. For all statistical analysis the confidence level at $\mathrm{p}<0.05$ was considered significant.

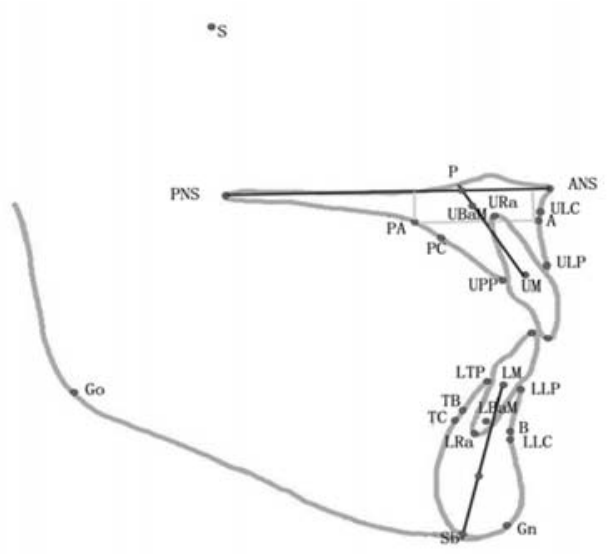

Figure 1: Cephalometric reference points

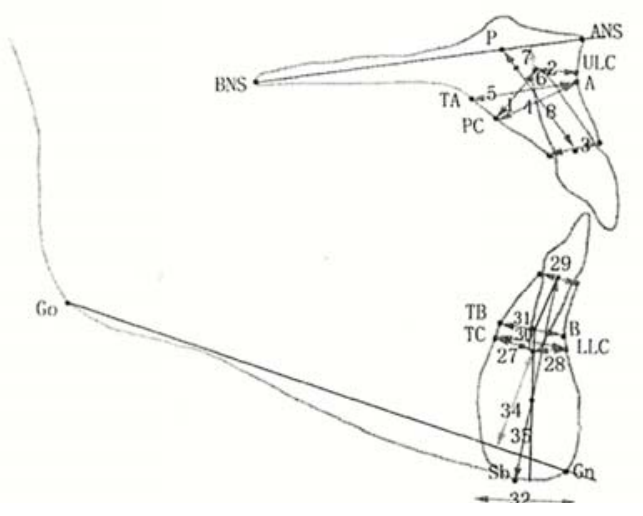

Figure 2: Linear measurements of central incisor regions

The research subjects were divided according to criteria of SN-MP. The proportion of male subjects with high angle was $20.3 \%$, average angle $50 \%$, and low angle $29.6 \%$. The proportion of female with high angle was $28.35 \%$, average angle $47.7 \%$, and low angle $23.8 \%$.

\section{RESULT}

The results of the present research are tabulated in Tables 1-5. Among different vertical skeletal facial types, high angle male and female individuals showed less maxillary incisor alveolar bone thickness at apical area (MxAD) and basal bone thickness $(\mathrm{MxBaD})$ compared to low and average angle subjects; while mandibular incisor alveolar basal bone thickness in female did not show any statistically significant difference but mandibular incisor basal bone thickness in male was more in low angle compared to high and average angle subjects. 
Maxillary and mandibular alveolar bone thickness at apex ratio $(\mathrm{AI}=\mathrm{MxAD} / \mathrm{MdAD})$, in high angle male subjects showed more value than average and low angle males; while female subjects did not show statistically significant difference. The smallest distance from upper incisor root apex to palatal side (U1R to PC) was longer in low angle male and female together compared to average angle male and female and also to high angle female. Similarly, the smallest distance from lower root apex to lingual cortex (TC point) showed more in low angle male and female than high angle male and female subjects. The distance from lower incisors root apex (L1R-LLC) to lower labial cortical bone of mandible at symphysis area (LLC) showed smallest distance in high angle male and female compared to average angle male and female and low angle male and female together. The mandibular alveolar bone thickness at the apex, the distance from lower labial cortex (LLC) to lingual cortex (TC) represents MdAD; showed thicker in low angle male and female together compared to average and high angle male and female together. The ratio between the distance of lower labial alveolar bone edge to lower lingual palatal alveolar bone edge and distance of mandibular cortical bone LLC to TC point (MdPAI) illustrated highest in high angle male and female subjects compared to average angle male and female and low angle male and female subjects.

Table 1: Mean and standard deviation (analysis of variance and pairwise comparison) of maxillary and mandibular incisor jaw bone measurements in each vertical skeletal type male subjects

\begin{tabular}{|c|c|c|c|c|c|c|}
\hline \multirow{2}{*}{$\begin{array}{l}\text { Measurement } \\
\quad \text { (in } \mathrm{mm} \text { ) }\end{array}$} & \multicolumn{2}{|c|}{$\begin{array}{l}\text { Average angle } \\
\quad(\mathrm{N}=27)\end{array}$} & \multicolumn{2}{|c|}{$\begin{array}{l}\text { High angle } \\
(\mathrm{N}=11)\end{array}$} & \multicolumn{2}{|c|}{$\begin{array}{l}\text { Low angle } \\
(\mathrm{N}=16)\end{array}$} \\
\hline & Mean & SD & Mean & SD & Mean & SD \\
\hline MxPD & 6.58 & 0.57 & 6.47 & 0.72 & 6.72 & 0.48 \\
\hline$M x A D$ & 11.75 & 2.07 & $10.57 \#$ & 1.44 & 12.68\# & 1.85 \\
\hline MxBAD & 16.93 & 2.95 & $15.01 \#$ & 2.3 & 18.07\# & 2.7 \\
\hline MdBaD & $8.08^{*}$ & 1.28 & $6.82^{*}$ & 1.69 & $9.06 *$ & 1.21 \\
\hline
\end{tabular}

Table 2: Mean and standard deviation (analysis of variance and pairwise comparison) of maxillary and mandibular incisor jaw bone measurements in each vertical skeletal type female subjects

\begin{tabular}{|c|c|c|c|c|c|c|}
\hline \multirow{2}{*}{$\begin{array}{l}\text { Measurement } \\
\quad \text { (in } \mathrm{mm} \text { ) }\end{array}$} & \multicolumn{2}{|c|}{$\begin{array}{l}\text { Average angle } \\
\quad(\mathrm{N}=32)\end{array}$} & \multicolumn{2}{|c|}{$\begin{array}{l}\text { High angle } \\
(\mathrm{N}=19)\end{array}$} & \multicolumn{2}{|c|}{$\begin{array}{l}\text { Low angle } \\
\qquad(\mathrm{N}=16)\end{array}$} \\
\hline & Mean & SD & Mean & SD & Mean & SD \\
\hline MxPD & 6.23 & 0.47 & 6.67 & 2.11 & 23.39 & 66.33 \\
\hline MxAD & 10.51@ & 1.54 & $10.21 \#$ & 2.75 & 12.88@\# & 2 \\
\hline MxBAD & 14.90@ & 2.09 & $14.45 \#$ & 2.73 & 17.11@\# & 2.91 \\
\hline MdBaD & 7.47 & 1.37 & 6.83 & 1.27 & 8 & 1.62 \\
\hline
\end{tabular}

Table 3: Mean and standard deviation (analysis of variance and pairwise comparison) of ratio Al measurement in each vertical skeletal type male and female subjects

\begin{tabular}{c|c|c|c|c|c|c|c|}
\hline $\begin{array}{c}\text { Measurement } \\
\text { (in mm) }\end{array}$ & Arch & \multicolumn{2}{c}{$\begin{array}{c}\text { Average angle } \\
\text { (N=27) }\end{array}$} & \multicolumn{2}{c|}{$\begin{array}{c}\text { High angle } \\
\text { (N=11) }\end{array}$} & \multicolumn{2}{c}{$\begin{array}{c}\text { Low angle } \\
\text { (N=16) }\end{array}$} \\
Al & Mean & SD & Mean & SD & Mean & SD \\
$\mathrm{Al}$ & Maxillary & $1.62 \&$ & 0.32 & $1.87 \& \#$ & 0.41 & $1.56 \#$ & 0.22 \\
\hline
\end{tabular}


Table 4: Mean and standard deviation (analysis of variance and pairwise comparison) of maxillary incisor jaw bone measurements in each vertical skeletal type between male and female subjects

\begin{tabular}{|c|c|c|c|c|c|c|}
\hline \multirow{2}{*}{$\begin{array}{l}\text { Measurement } \\
\quad \text { (in } \mathrm{mm} \text { ) }\end{array}$} & \multicolumn{2}{|c|}{$\begin{array}{l}\text { Average angle } \\
\quad(\mathrm{N}=59)\end{array}$} & \multicolumn{2}{|c|}{$\begin{array}{l}\text { High angle } \\
\qquad(\mathrm{N}=30)\end{array}$} & \multicolumn{2}{|c|}{$\begin{array}{l}\text { Low angle } \\
\qquad(\mathrm{N}=32)\end{array}$} \\
\hline & Mean & SD & Mean & SD & Mean & SD \\
\hline U1R-PC & 6.94@ & 1.84 & $6.31 \#$ & 1.5 & 8.06@\# & 2.21 \\
\hline U1R-ULC & 4.16 & 1.38 & 4.21 & 2.4 & 4.76 & 1.74 \\
\hline MiPad & 0.59 & 0.09 & 0.64 & 0.1 & 1.07 & 2.98 \\
\hline MxABI & 0.71 & 0.08 & 0.72 & 0.15 & 0.73 & 0.09 \\
\hline
\end{tabular}

Table 5: Mean and standard deviation (analysis of variance and pairwise comparison) of combined measurements of mandibular segments between male and female

\begin{tabular}{|c|c|c|c|c|c|c|}
\hline \multirow{2}{*}{$\begin{array}{l}\text { Measurement } \\
\quad \text { (in } \mathrm{mm} \text { ) }\end{array}$} & \multicolumn{2}{|c|}{$\begin{array}{l}\text { Average angle } \\
(\mathrm{N}=59)\end{array}$} & \multicolumn{2}{|c|}{$\begin{array}{l}\text { High angle } \\
(\mathrm{N}=30)\end{array}$} & \multicolumn{2}{|c|}{$\begin{array}{l}\text { Low angle } \\
(\mathrm{N}=32)\end{array}$} \\
\hline & Mean & SD & Mean & SD & Mean & SD \\
\hline L1R-TC & 3.56 & 0.95 & 3.21\# & 0.68 & 3.86\# & 0.85 \\
\hline L1R-LLC & $3.55 \&$ & 1.19 & $2.84 \& \#$ & 0.86 & $4.06 \#$ & 1.21 \\
\hline MdPD & 5.64 & 0.64 & 5.53 & 0.56 & 5.56 & 0.64 \\
\hline MdAD & $7.62 \&$ & 4.16 & 6.01\&\# & 1.13 & 7.85\# & 1.54 \\
\hline MdAD & 1.33 & 2.24 & 1.54 & 1.82 & 1.48 & 2.22 \\
\hline L1R-GoGn & $17.53 \&$ & 2.51 & 19.40\&\# & 2.93 & $17.29 \#$ & 2.31 \\
\hline MdPAI & $0.82^{*}$ & 0.2 & $0.95^{*}$ & 0.2 & $0.72^{*}$ & 0.14 \\
\hline MdABI & 1.01 & 0.76 & 0.9 & 0.13 & 0.92 & 0.1 \\
\hline
\end{tabular}

\# : means there is difference between high angle and low angle

@ : means there is difference between average angle and low angle.

: means there is difference between high angle, low angle and average angle.

\& : means there is difference between high angle and average angle

\section{DISCUSSION}

Orthodontic tooth movement can correct dental malocclusion to the extent that the distant effects can change the jaw growth pattern and also possibility of correcting the skeletal malocclusion. The difference in the incisor jaw morphology of maxillary and mandibular jaw bone thickness with Class II Division 1 malocclusion among different vertical facial types between gender were discussed in detail. The anatomic limits set by the labial and lingual cortical plates of the anterior alveolus at the incisor apex may be regarded as "orthodontic walls." ${ }^{10}$ In order to correct the anteroposterior and vertical discrepancies, there must be sufficient alveolar bone to move the incisors in adequate desired direction. The question arises in our mind how much required movement of incisors were possible without crossing these anatomic limits such that it may prevent palatal perforation, bone loss and root resorption. Since Class II Division 1 malocclusion phenotype was characterized by abnormalities in both dentoalveolar and skeletal abnormalities, only trying to compensate the skeletal discrepancies through alveolar remodeling could not succeed in biological ground, ${ }^{11}$ so if the skeletal discrepancy was large and beyond dental compensation thin alveolar housing was not enough for skeletal remodeling. Present study showed the thickness of the maxillary and mandibular incisor alveolar jaw bone at apex; that is higher in low mandibular plane angle than in high and average mandibular plane angle male and female subjects. Maxillary and mandibular incisor basal bone thickness $(\mathrm{MxBaD}, \mathrm{MdBaD})$ were more in low angle than 
high angle and average angle male and female which was in agreement with the studies done by Handelman et $a l^{10}$ Beckmann et al, ${ }^{12-14}$ Akira et $a l^{15}$ Sunwei ${ }^{4,16}$ and Hatairat $e t$ al. ${ }^{17}$ The area between point $\mathrm{A}$ and point $\mathrm{B}$ in both upper and lower incisor and point PA,PC, TB and TC were traced labially and lingually in order to consider the anatomic limitation landmarks for movements of root extent across the labial and lingual cortical plates. This result showed that, incisor root apex was more close to palatal cortex of maxillary bone at incisor area and symphysis of the mandibular bone in high angle than in low and average angle male and female subjects.

\section{CONCLUSION}

1. At the upper incisor, the vertical skeletal facial type is significantly correlated with both alveolar bone thickness and distance between the root apex from palatal, lingual and labial cortex.

2. Among different vertical facial types with Class II Division 1 malocclusion; early permanent dentition may accord to establish discriminate values as a sample to set up the cephalometric standard for the appropriate diagnosis to provide better treatment planning for the clinician.

\section{REFERENCES}

1. Edwards JG. A study of the anterior portion of the palate as it relates to orthodontic therapy. Am J Orthod 1976:69:249-73.

2. Ten Hoeve A, Mulie RM. The effect of the anterioposterior incisor repositioning on the palatal cortex as studied with laminography. JCO 1976:10:804-22.

3. Mulie RM, Ten Hoeve. The limitations of tooth movement within the symphysis studied with laminography and standardized occlusal films. JCO 1976:10:882-93.

4. Sun Wei, Zhou Li. A cephalometric study of incisal jaw morphology of normal occlusion subjects. hua xi kou qiang yi xue Za Zhi, 2005.

5. Remmelink HJ, Van der Molen AL. Effects of anterioposterior incisor repositioning on the root and cortical plate: A follow-up study. JCO 1984:18:42

6. Reitan K. Influence of variation in bone type and character on tooth movement on different alveolar bone types. Angle orthod 1964:3:24455.

7. Kurol J, Thilander B. Infraocclusion of primary molars and the effect on occlusal development, a longitudinal study. Eur J Orthod 1984;6:27793.

8. Murakami T, Yokota S, Takahama Y. Periodontal changes after experimentally induced intrusion of the upper incisors in Macaca fuscata monkeys. Am J Orthod and Dentofacial Orthop 1989:95:115-26.

9. Engelking G, Zachrisson BU. Effect of incisor repositioning on the monkey peridontium after expansion through the cortical plate. AJO-DO 1982; 82:23-32.

10. Handelman CS. The anterior alveolus: Its importance in limiting orthodontic treatment and its influences on the occurrence of iatrogenic sequel. Angle Orthod 1996:66:95-110.

11. Murray C, meikle.The dentomaxillary complex and overjet correction in Class II Division 1 malocclusion. AJO-DO 1998 volume 1980 Feb:184197.

12. Bechmann SH, Segner D. Changes in the alveolar morphology during open bite treatment and of treatment results. Eur J Orthod 2002; 24:391406.

13. Bechmann SH, Kuitert R,B, Prahl- Andersen B, Segner D. Alveolar and skeletal dimensions associated with lower face height. AJO-DO 1998;113:498506.

14. Bechmann SH, Kuitert R,B, Prahl- Andersen B, Segner D. Alveolar and skeletal dimensions associated with overbite . AJO-DO.1998;113:44352.

15. Akira H, Hitoshi H, Kazuhide K. Correlation between cortical plate proximity and apical root resorption. AJO-DO 1998;114:311-8.

16. Sun Wei, Zhou Li, Bai D, Zhau MY. K. Cluster analysis of incisal jaw morphology of normal occlusion subjects among different vertical skeletal types. 2005 Aug:23(4)299-302.

17. Hatairat Vitchuyanon, Surachai Dechkunakorn. Anterior dentoalveolar height, width and length in orthodontic patients among various vertical skeletal patterns. Fac of grad studies, Mahidol Univ May 20, 2005. 